\title{
Land Management Problems in the Mining Communities of Tarkwa, Ghana -A Look at Boundary Markers and Resurveys*
}

\author{
${ }^{1}$ E. A. A. Kwesi, ${ }^{1}$ O. Simpson, ${ }^{1}$ J. K. Lawerty, ${ }^{2}$ A. Mends, ${ }^{2}$ C. Assencher and ${ }^{1}$ P. E. Baffoe \\ ${ }^{1}$ University of Mines and Technology, Tarkwa, Ghana \\ ${ }^{2}$ National Association of Graduate Teachers, Tarkwa
}

Kwesi, E. A. A., Simpson. O., Lawerty, J. K., Mends, A., Assencher, C. and Baffoe, P. E. (2021), "Land Management Problems in the Mining Communities of Tarkwa, Ghana -A Look at Boundary Markers and Resurveys", Ghana Mining Journal, Vol. 21, No. 1, pp. 11-21.

\begin{abstract}
Boundary resurveys have become necessary in most mining communities of Ghana, especially, Tarkwa and its environs due to pressure and alteration in land use and land cover by mining operations. Most of the boundary markers (pillars, trees, streams, hills, valleys, footpaths, etc.) used in the past have been destroyed by mining and other associated activities. This has led to many disputes about ground boundaries and ownership of land tracts in the area. To curb the incidences of such conflicts, it has become important to have more reliable and scientific demarcations and surveys of the old boundaries and owners of land tracts in the area for registration, using modern technologies in land surveying. Equipment and methods used over a century ago to mark and describe land boundaries in the area have become obsolete now, and modern equipment and methods, while capable of measuring to very high precisions, cannot automatically give or tell the right boundaries and owners of land tracts established centuries ago. This paper examines the land boundaries situation in the study area, the impacts of mining on this, the need for boundary retracement surveys, the challenges that the rampant destruction of boundary markers in mining communities pose to such resurveys, and offers suggestions on dealing with these challenges in the management of land in the area. It also provides helpful information to land owners, land 'buyers' and land surveyors on the effects of the boundary problems on land transactions, surveys and registration in mining areas.
\end{abstract}

Keywords: Surface Mining, Boundary Markers, Retracement Surveys, Land Conflicts and Management

\section{Introduction}

The economic boom of mining in the few decades past has contributed to high rates of migration, population growth, urbanization, and high pressures over socio-economic facilities in mining communities in Ghana, particularly in Tarkwa and its environs (Kwesi, et al., 2018; Anon., 2014; .Adjei et al., 2012; Kusi-Ampofo and BoachieYiadom, 2012; Kuma and Ewusi, 2009). One area of interest or concern to land surveyors is the pressure on land and its associated problems in the acquisition, survey and registration of land parcels. Land acquisition in the Tarkwa mining areas has come to involve the resurvey and registration of old boundaries and parcels whose physical evidence on the ground have been destroyed decades ago. The destruction of the physical evidence of boundaries may be blamed on mining (both large and small scale) and its allied activities, expansion of human dwellings and other socio-economic activities (like the development of communication lines, waterworks, markets, schools and recreational facilities). Many towns, families, clans or stools that used to live distances (kilometers) apart have now merged and overlapped due to urbanisation and other developmental activities associated with mining. Some lands that were given out as concession to mining companies in the past have now come under human dwellings and other socialeconomic uses other than mining operations, whiles some dwelling places (lands) have come under mining ('galamsey') activities (Kwesi, et al., 2018;
Anon., 2014; Adjei et al., 2012; Kuma and Ewusi, 2009). Concessions and other land tracts have changed ownership from one exploration or mining company to another over the years. In some areas, it is difficult to tell whether the land belongs to a family or a stool or a company and which family or stool or company is the rightful owner. Some settlers and house owners do not know the rightful owners of the lands where they have built and thus have been paying multiple royalties to different families or stools that claim ownership over the same land. Other settlers do not pay anything at all due to the confusion.

The above land boundary and ownership problems have resulted in some confusion, abuse, conflicts, undue delays, and extra expenses in land transactions in the area. To help deal effectively with these problems, there is the need for surveyors and land buyers to have some knowledge and understanding of the underlying boundaries problems and how this may affect the acquisition, surveying, and registration of land parcels in the area. To that end, this paper reviews the theoretical rules and principles of boundary retracement surveys, discuses the challenges that the rampant destruction of boundary markers in mining communities pose to such resurveys, and offers suggestions on dealing with the challenges. The sections that follow address these. 


\subsection{Theoretical Background}

Retracement surveys, also called resurveys, are surveys required for restoring evidence of the location of a previously established boundary, following as closely as possible, the footsteps of the original surveyor (Griffin, 1960; Hermansen, 1991; Troy, 2006). Early surveyors employed less precise methods and equipment (e.g. Compass and chain and later the theodolite and tape) in establishing many of the boundaries that may need retracement and resurvey today. Due, perhaps, to field obstacles and other limitations, these methods and equipment were often applied incorrectly, adjustment of measurements and documentation of survey were often not rigidly done as required by the science of surveying and positions were determined and described in relative instead of absolute terms, and reference points involved natural and temporal features that later became obliterated (BorshchKomponiets et el., 1989; Anderson, 1998; RoseNolin, 2008; Ghilani and Wolf, 2008; Anon, 2009). As a consequence, inconsistencies and errors in measurements were so common in early surveys that measurements were not held in high regard (Hermansen, 1999). To resolve ambiguities between what was marked and what was measured, the courts adopted rules, known as principles or rules of construction that are meant to be applied in a consistent manner where there is conflicting information. Many of these rules still apply and should serve as guiding principles for retracement surveys. Two of the fundamental rules of construction of retracement surveys are that:

(a) the retracing surveyor is charged with following in the footsteps of the original surveyor.

(b) the original boundary fixed by the original surveyor, as imperfectly as the boundary may have been measured and documented, remains the boundary (Griffin, 1960; Hermansen, 1999).

Thus, once the boundaries of a piece of land have been demarcated, surveyed, documented and accepted or approved by relevant parties or stakeholders, its boundaries should not be altered by subsequent resurveys of that land. Accordingly, the primary concern of a surveyor in retracement surveys should be the locating of the monuments placed by the original surveyor, or, where such monuments no longer exist, the locating of the places where they originally stood.

\subsubsection{Principles for Resurveying Old Boundaries}

To adhere to the above rules and be successful in retracement surveys, a number of principles, standards and legislative instruments or acts have been discussed in the literature to guide surveyors in executing retracement surveys (Anon. 1932; Anon.
1962; Davis et el., 1981; Anon, 2008). Some of these principles are summarized below:

(i) Original monuments or the former locations of the monuments are superior to the survey measurements taken to determine the locations of boundaries. The reason for this may be that, even though the collection and computations of field measurements are important, they are often not the critical components of boundary retracement (Hermansen, 1999).

(ii) Research into operating legal documents (deeds, records of survey, boundary line agreements, etc.), field reconnaissance and contacting former surveyors and landowners for undocumented survey records are often more important than the precision of measurements in locating the position of the original monuments (Hermansen and Brown 2006; Troy, 2006; Rose-Nolin, 2008; Garry, 2009; Lanfranc, 2013).

(iii) The old lines of occupation, witness marks, and the memories of the elderly are more compelling than the survey measurements.

(iv) In many boundary retracement surveys, there appear to be an inverse correlation between precise measurements and accurate measurements. As the precision of measurements increase, the accuracy (with respect to the original boundary) may decrease.

(v) Measurements that replicate the deficiencies of the original equipment are more accurate in locating the original bounds than precise measurements that remove or are not influenced by local anomalies and terrain conditions between two points.

Based on the above points, a surveyor may have a better chance of successfully retracing the original locations of old boundaries and parcels using primitive methods or instruments (like compass and tape) rather than modern ones (like GPS and other GNSS techniques) if the chain or tape and compass were used to establish the original boundaries (Hermansen, 1999; Ghilani and Wolf, 2008). It has been observed that failure to observe the rules and principles often results in erroneous and unacceptable retracement surveys and this may subsequently create additional or compound existing boundary problems (Wilson, 2009).

\subsection{Geographical and Economic Setting of Study Area}

The study area is Tarkwa and its surrounding mining communities, such as Bonsa, Tamso, Nsuta, Abosso, Bogoso, and Prestea. Fig. 1 is a map of the Tarkwa Nsuaem Municipal Area (TNMA) of Ghana 
showing the geographical location of Tarkwa. The municipal town, Tarkwa, is the main urban center serving the area. With very active mining (including widespread 'galamsey' operations) and associated commercial activities in the area, there is high influx of people from all walks of life into the area to settle and do business. This has contributed to a high population growth rate, high cost of living and accommodation, and rising pressures on land and other resources for socio-economic needs. With mining activities spreading all over the area, land for farming and residential needs is becoming scarce. These factors have contributed to the increasing land boundary and ownership, waste management and environmental pollution problems in the area. (Kusi-Ampofo and Boachie-Yiadom, 2012; Kuma and Ewusi, 2010; Anon., 2009; Kwesi, et al., 2018; Anon., 2014).

\subsection{Topography and Geology of Study Area}

As part of the Tarkwa mining areas, the topography of the study area is generally undulating with some scarps ranging from 150 - 300 meters above sea level with small scale mining operations frequently taking place along the ridges and valleys (Kwesi et al., 2018; Mantey, 2014; Anon., 2009, Asante, 2011; Adjei et al., 2012; Kusi-Ampofo and BoachieYiadom, 2012). Geologically, the area forms part of the Birimian and Tarkwain formations. Aquifers in the area are considered possessing dual and variable porosity and limited storage capabilities (Kuma and Ewusi, 2009; Asklund and Eldvall, 2005).

\section{Resources and Methods Used}

The materials used include plans and data of the old boundaries, court documents describing the locations of adjudicated boundaries, topographical maps and mine plans of concessions in the area and survey equipment like the tape, compass, theodolite, GPS receivers and field cameras. The methods used include, literature review and reconnaissance survey; searches through local, district, regional and national archives of Stool Lands, Survey and Mapping Division, Mineral Commission and Town and Country Planning Departments and offices of Chiefs and Traditional Councils for relevant documents; stakeholder discussions; and field interviews and observations for evidence of the locations of the old boundary points and lines and their conditions. The reconnaissance surveys were carried out to get first-hand information about the boundary and ownership problems in the mining areas of Tarkwa, Ghana. Those interviewed include the chiefs and stool elders, 'odikro' (caretaker chiefs), surveyors and other land agents in the area, miners, older folks, church leaders and those staying close to the boundary lines. The interviews were done randomly throughout the work but mainly during the reconnaissance and the field measurements.

The responses to the interviews were designed to be applied in two ways:

(a) to serve as a guide in tracing the boundaries of the old concession which were not in dispute but no longer evident on the ground, and

(b) to provide bases for the survey team's own evidence and assessment of where the disputed boundaries should be if called upon to provide information that will help ascertain the right locations of the boundaries in the disputed region.

The data, information and field observations gathered were sorted, grouped and analysed under various headings to impart more knowledge and understanding of the boundary problems under discussions.

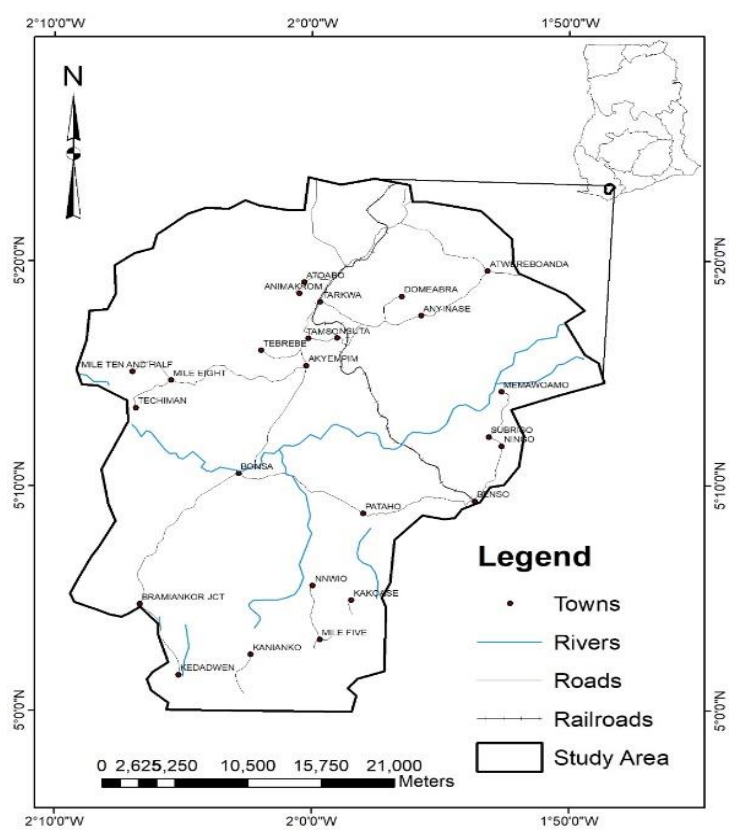

Fig. 1 Map Showing the Location of TNMA

\section{Results and Discussion}

\subsection{State of Historical Records and Evidence}

Some paper records and drawings of the old compass surveys of the land parcels, their supposed owners and boundaries were found, but there were very few or no ground markers or evidence to support these records for the correct judgement of where the boundaries should be and who should be the right owners. Some of the maps/plans and data sheets were faded and inconsistent with others and ground evidence found during the study. For 
example, the locations and nature of some communities and the topography at some places had undergone changes and so were no longer consistent with the information in the historical documents that were to serve as references for retracing the boundaries and resolving related disputes. Fig. 2 shows examples of these documents. In view of this, it became necessary to rely on narratives and assistance from the elderly and others in the communities for retracing the locations of boundary lines and markers. There were difficulties in getting consistent information on where the boundaries of some stools and families were to pass since almost all those who knew the boundary first-hand had died. Several people had to come in to show the boundaries and many showed different routes or courses.

\subsection{State of Boundary Markers}

The boundary markers found during the survey include government pillars (control points), mine concession monuments and massive stool land pillars set up in the 1930s and beyond (Fig. 3). Most of these permanent monuments set up in the past to mark stool, state and mining lands have been destroyed. Natural boundary markers like trees are gone, river courses and foot paths have been changed, hills have been levelled, and valleys have been filled. Many of the few permanent markers left are in very bad state, unstable and may soon be lost (Fig.3). Some boundary lines and markers were found running through or at the houses and offices of some people and companies (Fig. 3). The general attitude of peoples towards boundary markers was very bad. There is virtually no care or protection of these markers. They are indiscriminately being destroyed without any considerations for their importance in resolving boundary and ownership disputes and smooth acquisition and registration of land rights. Mining, activities, (especially 'galamsey'), infrastructure and residential developments were observed to be main factors of the destruction (Fig.3).

\subsection{Impacts of Destruction of Boundary Markers on Land Conflicts and Retracement Surveys}

As can be deduced from the above sections, the boundary problems have generally resulted in some confusions, abuses, conflicts, undue delays, and extra expenses in land transactions in the area. Specific ones that may be highlighted include:

(i) In some areas, it is difficult to tell whether the land belongs to a family or a stool or a company and which family or stool or company is the rightful owner. (ii) Some settlers and house owners do not know the rightful owners of the lands where they have built and thus have been paying multiple royalties to different families or stools that claim ownership over the same land. Other settlers do not pay anything at all due to the confusion.

(iii) Rightful compensations and/or royalties have either not been paid at all or paid to wrong owners or to the government coffers.

(iv) Some individuals may have authentic cadastral plans duly signed by licensed surveyors and official regional surveyors but have difficulties in registering such lands due to problems about the rightful ownership type (family, stool, state or private).

(v) Conflicting or overlapping cadastral plans that result from surveying wrong and overlapping boundaries that clients show surveyors for measurements - there are parcels with no demarcation marks (pillars) at all or that have multiples markers at different locations for the same points.

(vi) Due to overlapping boundaries of stool lands, there have been multiple sales, surveys and site plans of the same lands or parcels.

\subsection{Contributing Factors to Boundary Problems}

From the historical records, interviews, discussions and field observations, a number of points were deduced as contributing factors to the boundary and land dispute problems in the study area. These include:

(i) Location of Traditional Seats of Stools and Sizes of Concessions in the Past:- Traditional capitals were located far away from mining concessions, and mine operations may not have been that extensive and so there were little or no overlaps of stool lands in the past. As mining operations and settlements expanded, overlaps started to occur. Those closer to the concessions and faster to act, probably claimed ownership for compensation and royalties only for these to be contested later by other stools or families as belonging to them.

(ii)Relocation of Settlements/Communities:This displaces original families and communities far away from their lands. The nearby communities that now deal with the land more, may later claim ownership of it than the actual owners that may be relocated to dwell far away. 


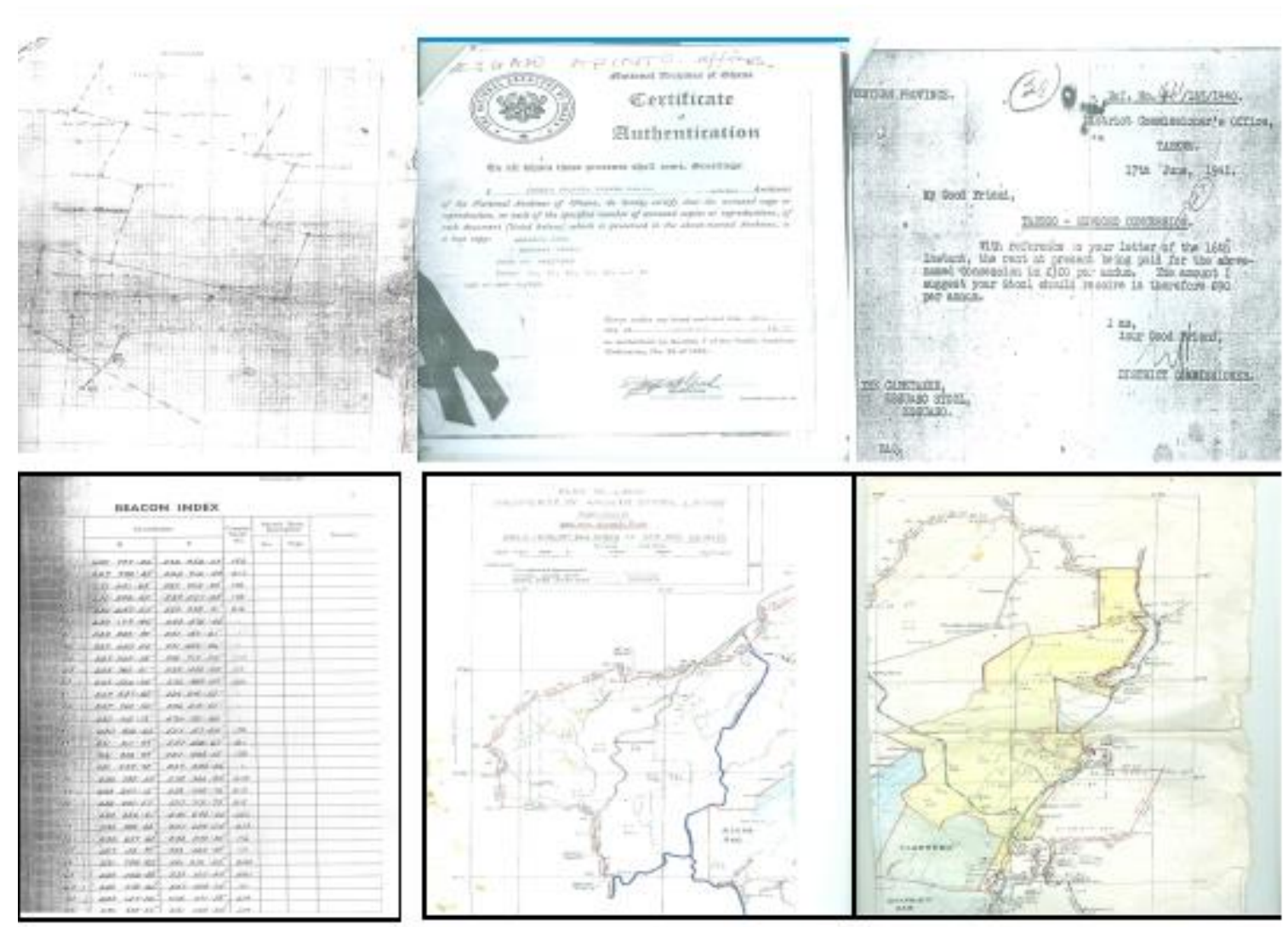

Fig. 2 State of Historical Records on Land Ownership and Boundary at Time of Resurvey
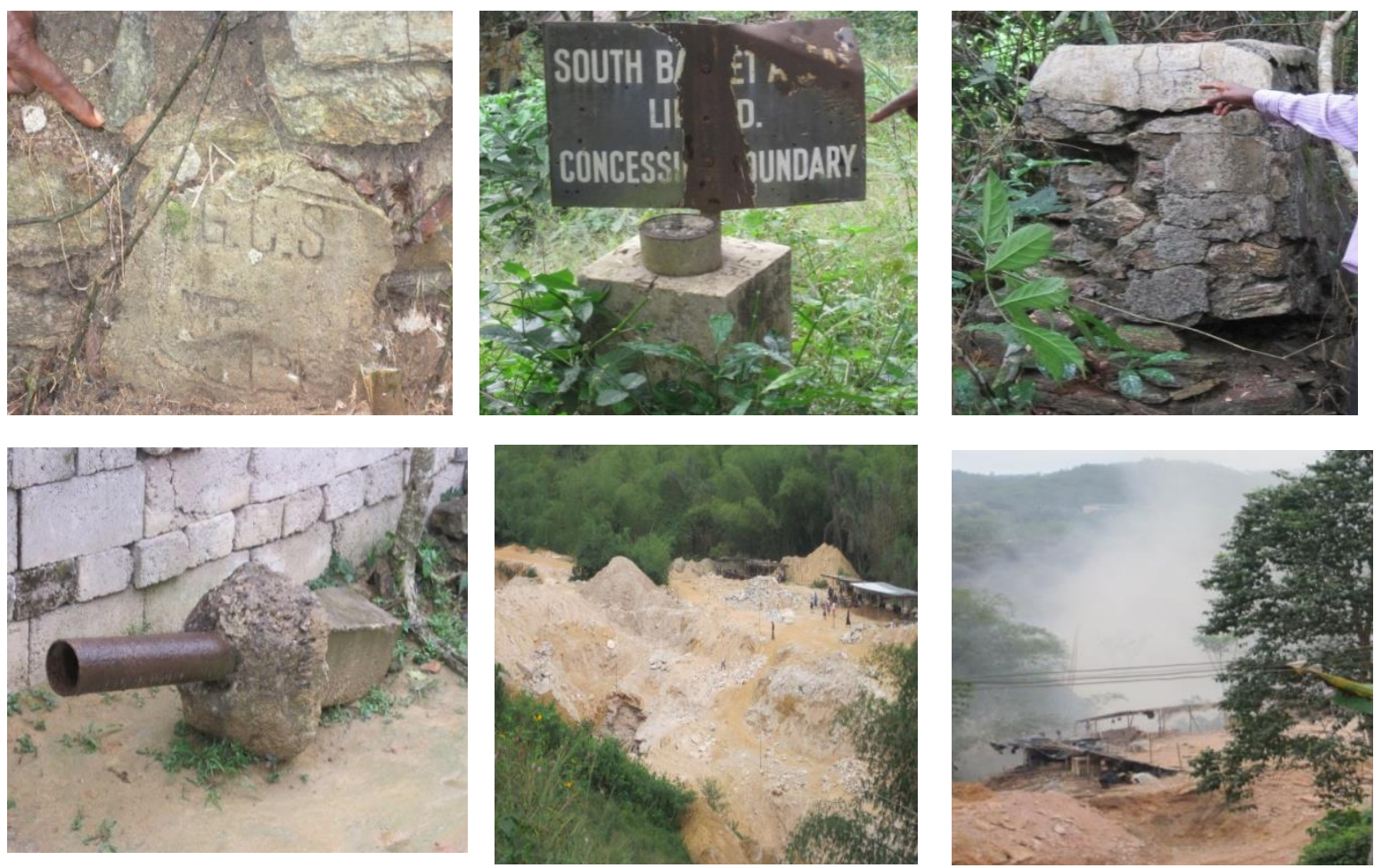

Fig. 3 State of Boundary Markers and nearby Mining Activities at Time of Retracement Survey 
(iii) Farm Compensation:- Farm owners are compensated for with documents that includes survey plans of their farm lands bearing their names as owners of the farm. If the right owners of the land itself are not documented well, in future, children of these settler farmers may claim ownership of such lands referring to such compensation plans that bear their parent's names as evidence.

(iv) Construction Activities:- The operations of mining (legal and illegal), its allied companies and expansion of settlements and socio-economic developments have also been destroying boundary pillars and other makers of land parcels with no provision made to relocate or document the pillars and their coordinates (some relics of boundary pillars are found in peoples rooms and compounds). Fig. 3 show examples of these situations on the ground.

(v) Delays in executing court decisions on boundary demarcations and surveys

(vi) Lack of effective institutional systems for protecting and preserving boundary markers

\subsection{Past Re-surveying Attempts in the Area}

Between 2000 and 2013, some survey projects were embarked upon to solve some of the boundary retracement problems at Tarkwa. These projects were initiated and supported through the efforts of the local chiefs and their traditional councils, the regional administrator of stool lands and the Ghana Survey Department (now Survey and Mapping Division). In one such case, the work required tracing the old boundaries of two disputing stools (A and $\mathrm{B}$ ) and that of a mine (TMS) concession running through a region claimed by both stools and restoring $30 \%$ of the concession in that region and the associated royalties to one of the stools based on court rulings and documents dating back to the 1910-1907. Excerpts of this are discussed in the sections that follow. Due to permit, administrative and security issues, the names and measurements (coordinates, distances and areas) presented in this paper have been altered from the real ones on the ground.

\subsubsection{Challenges Involved}

The boundaries were mostly described in terms of bearings and distances to or from features that no longer existed or were known to those living at the time of the survey. There were also difficulties in getting first-hand information on where the boundaries of the old concession were to pass since almost all those who knew the boundary very well had died. Several people had to come in to show the boundaries and many showed different routes or courses. Furthermore, efforts to trace the boundary points and lines from topographic features like road intersections, rail lines, culverts and bridges that appeared on topographic maps of the area did not yield the needed fruitage because the lines and points were running and falling through houses, offices, stores and other built-up areas that were practically difficult to access.

Due to the above and other challenges, the original goal of tracing the old boundaries, based on the descriptions in the court rulings and other documents, and restoring $30 \%$ of the TMS concession to one of the stools could not be pursued. Also, the TMS concession had changed hands over the years and was currently part of a bigger concession belonging to a modern mining company (TGA) in the area. It was thus suggested that the two stools would show their boundaries independently (to the best of their knowledge and in conjunction with evidence in the documents) for them to be surveyed and superimposed on the TGA concession in the disputed area to access how much of the concession would fall into the boundary of each stool. This was agreed and pursued but with other difficulties such as delays in getting the necessary support from both sides in terms of data, funds, man power and other logistics.

\subsubsection{Boundary Resurvey and Plotting}

Despite the challenges encountered, sections of the stool boundaries in the region of dispute were identified for re-surveying. Each stool showed its boundary for surveying separately. Samples of the results in a form of Tables are displayed in Table 1, Table 2, Table 3 and Table 4 . The boundaries surveyed were plotted and superimposed on the portion of the TGA concession boundary in the dispute region as shown at Fig.4. There are portions that are common to the two stools and portions that overlap. It is helpful to note that the section under discussion is the portion bounded by two government pillars Labelled CBPS and CBPN respectfully at the south-western and north-eastern parts of the region of dispute, where the two stool boundaries coincide. This portion spans a distance of about $11600 \mathrm{ft}(3.5 \mathrm{~km})$. Pillar CBPN is already uprooted and lying down in the house of a resident (Fig. 3) and its exact location is lost and so needs to be restored and protected as soon as possible. The conflicting portions are to be resolved by agreeing to a common boundary to be decided between the two stools. The road and towns or settlements on the plan help to locate the boundaries of interest within the broader geographical region of the locality (Fig. 5). 
Using the coordinates and the intersections of the boundaries, area estimates (based on the coordinate's method) were made as provisional values for estimating the percentages of the concession falling under each stool land within the dispute region from CBPS to CBPN. The values obtained were as follows:

(i) Area of overlap between the boundaries of the two stools is estimated to be 85.3 acres.

(ii) The part of the concession under dispute claimed by stool $\mathrm{A}$ is the area bounded by the boundaries of TGA and Stool A from CB1 to CB3 on the plan, and this is estimated to be 81.05 acres. This is also the total area of the concession under disputed.

(iii) Similarly, the part of the concession under dispute claimed by Stool B is the area bounded by the TGA boundary from $\mathrm{CB} 1$ to $\mathrm{CB} 2$, the boundary of Stool A from $\mathrm{CB} 1$ to $\mathrm{CB} 3$, and the boundary of Stool B from CB2 to CB3, and this is estimated to be 53.88 acres.

(iv) Percentage of disputed concession area being claimed by stool B is $66.48 \%$.

(v) If the total royalty Stool $\mathrm{A}$ is getting is proportional to the area of concession under $\mathrm{A}$ in the disputed region, then the percentage of the royalties that should go to Stool $\mathrm{B}$, assuming the boundary of Stool B is accepted as the correct boundary, will be $66.48 \%$.

It must be noted that the estimates in this paper should not be taken as correct values for sharing of the actual royalties since almost all the boundaries in this project are in dispute. These boundaries were shown separately and independently by representatives of the two stools and the surveyor acted as a neutral and obedient servant to survey what was shown him, at this stage of the project. Also, the interview results have had no bearing on the stool boundaries surveyed and presented in this paper. However, in the absence of reliable and acceptable relocation of the 1910 boundaries, the area computations in this project may be used for negotiations and adjudication of the right locations of the boundaries and percentages of royalties that should go to each stool.

\subsection{Suggestions for the Way Forward}

The following suggestions are put forward for consideration in dealing with the current and future issues about the boundary conflicts and resurveys attempts to fix them.

(i) Establishing New Boundaries: - In the absence of adequate and reliable evidence to retrace the original boundaries, new boundaries may have to be decided upon by a court process and/or agreement between parties for the establishment of new boundaries.

(ii) Use of Absolute and National Coordinate Systems for Boundary Survey Data:- There is need to process and store survey data on boundaries in absolute and national coordinate system such as the Ghana National Grid or UTM, so that if the markers or pillars are destroyed, it will be easy to restore them back (using the coordinates). Updating and conversion of old boundary data (such as bearings and/or distances referenced to non-permanent features) into modern coordinates systems and data formats may be helpful in preventing some of the problems.

(iii) Protection of Boundary Markers:- Existing boundary markers should be protected and reinforced. New boundary markers should be of permanent materials. Monitoring/Surveillance of boundary pillars by local land owners and surveyors can be helpful. Legal and institutional backing to protect boundary markers from destruction will be a necessary step for the way forward. Furthermore, regularly educating the public and all stakeholders as to the importance to be attached to survey pillars can be helpful.

Table 1 Sample of the Coordinates of Boundary Points of Stool A in Disputed Region

\begin{tabular}{|c|c|c|}
\hline $\mathbf{N}(\mathbf{f t})$ & $\mathbf{E}(\mathbf{f t})$ & Label \\
\hline 224801.80 & 545558.51 & $\mathrm{~A} 1$ \\
\hline 224652.26 & 544810.82 & $\mathrm{~A} 2$ \\
\hline 224614.88 & 544287.44 & $\mathrm{~A} 3$ \\
\hline 224072.80 & 542904.21 & $\mathrm{~A} 4$ \\
\hline 224521.42 & 542642.52 & $\mathrm{~A} 5$ \\
\hline 224297.11 & 541913.52 & $\mathrm{~A} 6$ \\
\hline 224278.42 & 541595.75 & $\mathrm{~A} 7$ \\
\hline 224502.72 & 541464.91 & $\mathrm{~A} 8$ \\
\hline 224465.34 & 540922.83 & $\mathrm{~A} 9$ \\
\hline 225568.18 & 539147.07 & $\mathrm{~A} 10$ \\
\hline
\end{tabular}

Table 2 Sample of the Coordinates of Boundary Points of Stool B in Disputed Region

\begin{tabular}{|c|c|c|}
\hline $\mathbf{N}$ (ft) & $\mathbf{E}(\mathbf{f t})$ & Label \\
\hline 225144.43 & 545360.16 & B 1 \\
\hline 224695.81 & 542780.63 & B 2 \\
\hline 224639.74 & 541958.17 & B 3 \\
\hline 225144.43 & 539939.41 & B 4 \\
\hline 225480.89 & 539173.02 & B 5 \\
\hline 225910.81 & 539154.33 & B 6 \\
\hline 225985.58 & 538780.49 & B 7 \\
\hline 225686.50 & 538257.10 & B 8 \\
\hline 226501.95 & 536885.56 & B 9 \\
\hline 224693.48 & 535595.79 & B 10 \\
\hline
\end{tabular}


Table 3 Sample of the Coordinates of TGA

Concession Boundary Points in

Disputed Region

\begin{tabular}{|c|c|c|}
\hline $\mathbf{N}(\mathbf{f t})$ & $\mathbf{E}$ (ft) & Label \\
\hline 229028.06 & 545150.19 & C 1 \\
\hline 224965.61 & 545324.65 & C 2 \\
\hline 223594.84 & 545100.34 & C 3 \\
\hline 219557.32 & 544228.04 & C 4 \\
\hline 213276.72 & 544377.58 & C 5 \\
\hline 213426.26 & 540340.05 & C 6 \\
\hline 216641.32 & 541461.58 & C 7 \\
\hline 217164.71 & 540290.20 & C 8 \\
\hline 222249.00 & 541511.43 & C 9 \\
\hline 222548.08 & 540514.51 & C 10 \\
\hline
\end{tabular}

Table 4 Sample of the Coordinates of Road Points through Disputed Region

\begin{tabular}{|c|c|c|}
\hline $\mathbf{N}(\mathbf{f t})$ & $\mathbf{E}$ (ft) & Label \\
\hline 228997.09 & 536978.30 & $\mathrm{R} 1$ \\
\hline 228595.29 & 536529.23 & $\mathrm{R} 2$ \\
\hline 228158.04 & 536292.88 & $\mathrm{R} 3$ \\
\hline 227803.51 & 536103.80 & $\mathrm{R} 4$ \\
\hline 227413.53 & 535867.45 & $\mathrm{R} 5$ \\
\hline 226503.58 & 535122.94 & $\mathrm{R} 6$ \\
\hline 225510.91 & 535233.24 & $\mathrm{R} 7$ \\
\hline 224723.07 & 535248.99 & $\mathrm{R} 8$ \\
\hline 223541.32 & 534335.10 & $\mathrm{R} 9$ \\
\hline 223210.43 & 534319.35 & $\mathrm{R} 10$ \\
\hline
\end{tabular}

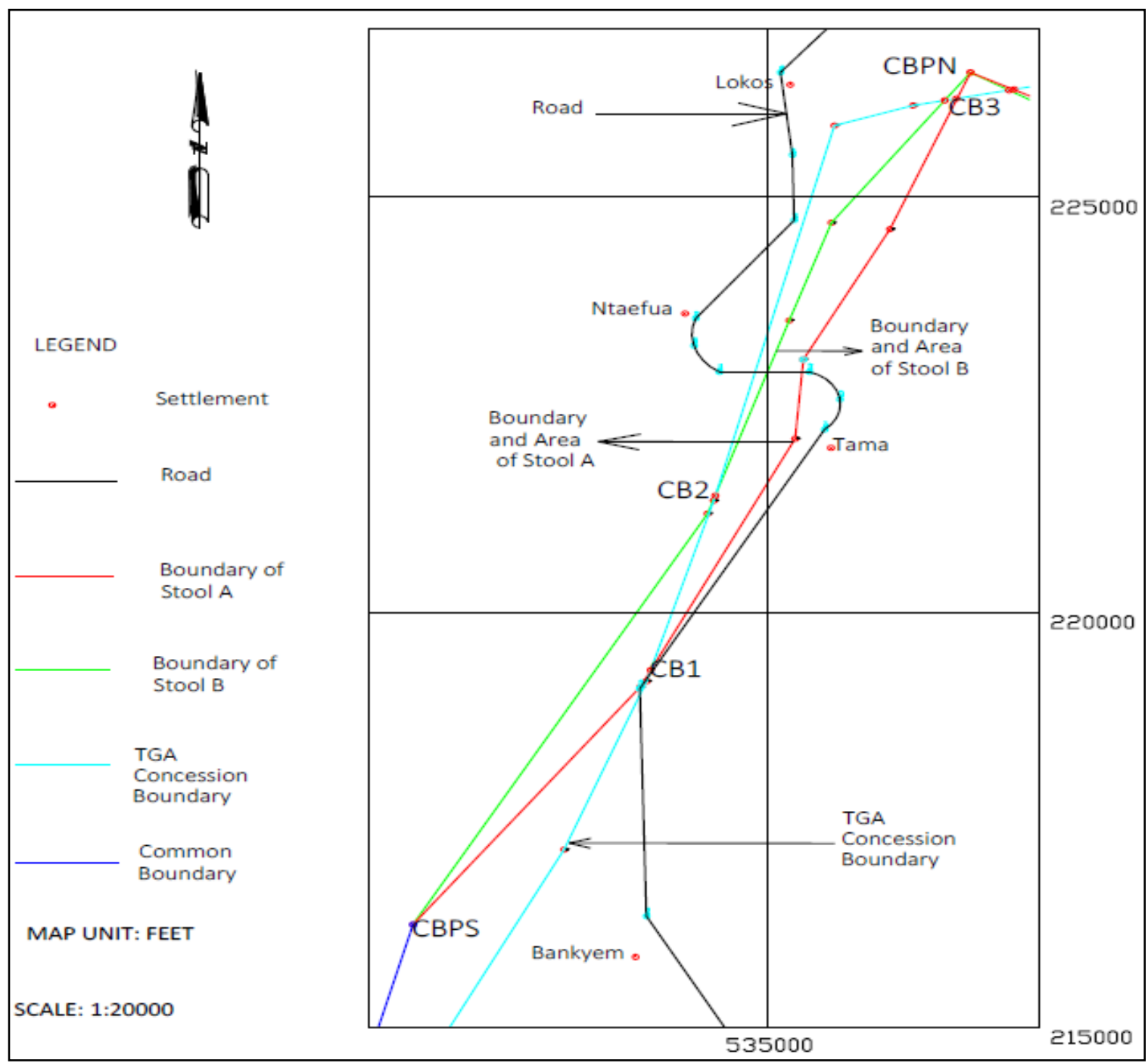

Fig. 4 Plan of Retraced Boundaries in the Dispute Region 


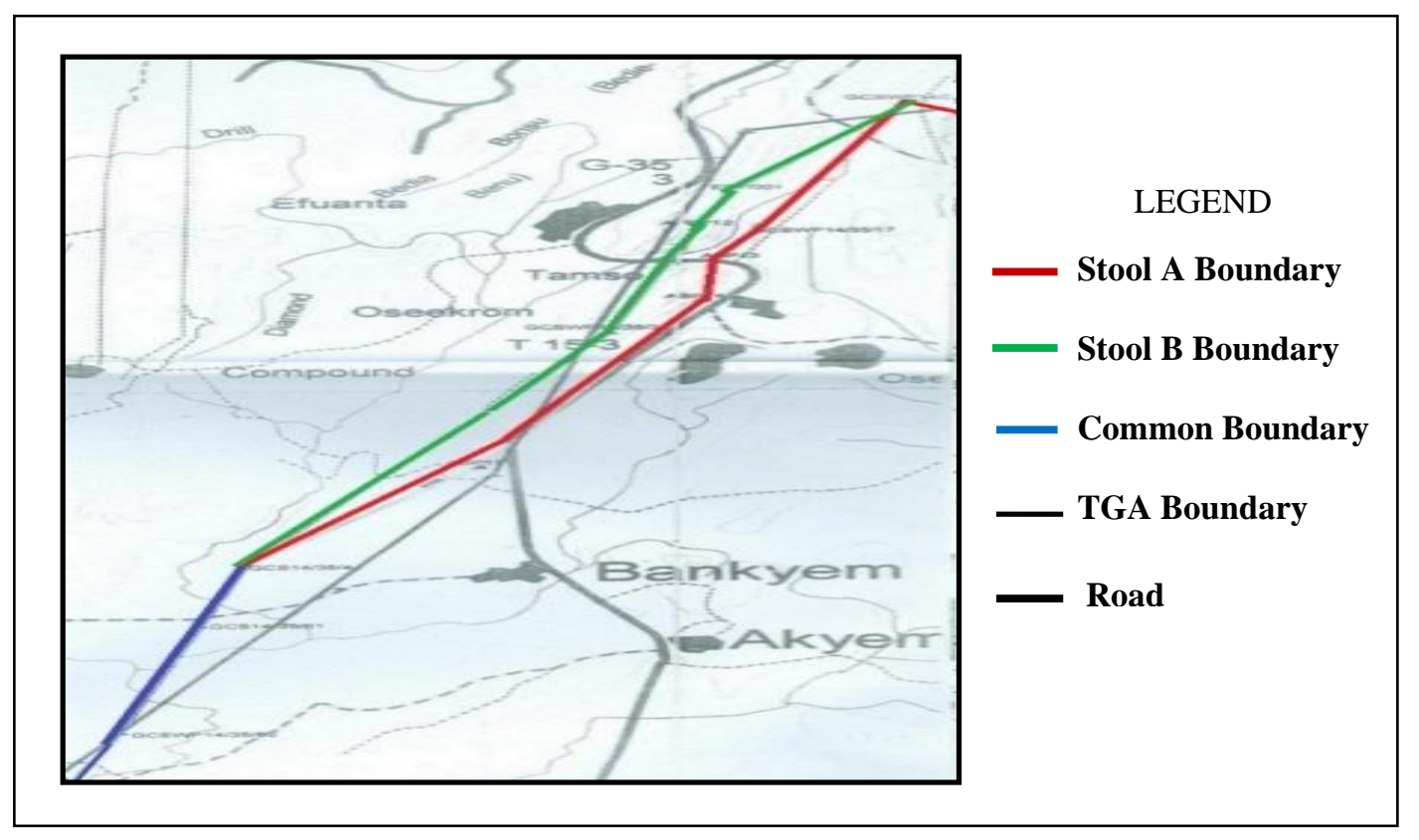

Fig. 5 Plot of Retraced Boundaries on Topographic Map of Area

(iv) Prompt Execution of Court Judgments on Land Boundaries:- Delays in executing court judgment regarding boundary demarcation and surveys should be avoided. It should be done while those involved and ground evidence are available to help and guide the execution of the decisions.

(vi) Role of Land Surveyors and Regulatory Personnel:- Using qualified Surveyors for boundary surveys should be encouraged. Land surveyors and regulatory personnel need to work with sound understanding of the problems of boundary disputes, and consideration of the changing technology for re-surveying what they do today tomorrow. They should pioneer the public education and offer professional advice to landowners, lawyers, chiefs, and land buyers about how to avoid and settle land disputes.

\section{Conclusions and Recommendations}

Boundary problems are one of the major sources of land conflicts in the Tarkwa mining communities of Ghana. Surface Mining Operations and its attendance urbanization has contributed significantly to the destruction and alterations of boundary markers (monuments) and traditional boundaries. This further poses serious setbacks and challenges to retracements surveys that are necessary for restoring old boundaries and resolving some of the land conflicts. Such challenges have also led to delays in the execution of surveys and court decisions in land conflicts resolution. In the face of these challenges, some stools, families, companies, and individuals continue to litigate about land boundaries, insisting on their rights instead of making concessions, whiles others resort to quick but disputable means of boundary settlement including the use of modern techniques like GNSS for boundary restoration without proper reference to the rudiments of retracement survey. This study has highlighted the fundamental rules that surveyors need to observe in retracement surveys for the resolution of land conflicts. A key among these is to relocate the original monuments and lines that define the original boundaries fixed or described in legal documents. As observed by Hermansen (1999), the ease and precision of GPS and other GNSS techniques should not make a surveyor detract from the fundamental responsibility to search for and retrace the original surveyor's footsteps in a retracement survey. If not used properly, these modern techniques can cause problems and errors in retracing boundaries. They must thus be used in conjunction with a thorough knowledge of the limitations of earlier surveys and the rules governing retracement surveys. It is recommended that the information and discussions presented in this paper should serve as a guide to all stakeholders that engage in land transactions in the area, to act properly and avoid adding to the problems. Further, it must be noted that the roles of land surveyors in the resolution of such boundary conflicts are critical. Therefore, stools, families, communities and all other stakeholders involved in such cases should ensure that only qualified (professional) surveyors are engaged for the demarcation and surveys or resurveys of boundaries and land parcels in mining and other communities prone to land conflicts such as Tarkwa and its environs. 


\section{Acknowledgements}

The authors acknowledge the support of and wish to thank late Licensed Surveyor T. K. Simpson and chiefs and elders of stools A and B for permission to use data on the boundary in dispute to illustrate the need for and challenges of boundary resurveys in mining communities; the administrator of Stool Lands, Lands Commission and Survey and Mapping Division for legal documents and survey data on the boundary and control points in the study area; the mining companies for data and support on the mine concession boundaries; and the Regional Surveyor (Takoradi) for his contribution as a mediator between the disputing stools and the survey team at various meetings to discuss some of the challenges met in executing the project.

\section{References}

Adjei, S., Oladejo N.K. and Adetunde I.A. (2012), "The Impact and Effect of Illegal Mining (galamsey) towards the Socio-economic Development of Mining Communities: A Case Study of Kenyasi in the Brong Ahafo Region", International Journal of Modern Social Sciences, 2012, 1(1), pp. 38-42.

Anderson, J. M. (1998), Surveying, Theory and Practice, McGraw-Hill Inc, pp. 801

Anon. (2014), "2010 Population \& Housing Census", District Analytical Report for the Tarkwa-Nsuaem Municipality', Ghana Statistical Service (GSS), Ghana, pp. 1-67.

Anon. (2009), "Galamsey in Wassa West District and Its Attendant Problems", the Ghanaian Chronicle, 18 September 2009 Issue, pp. 5-6.

Anon. (2009), "Manual of Instructions for Surveying Public Lands - 1973", U.S. Department of the Interior, Bureau of Land Management, Online Edition, Chap. VI, Available at http://www.cadastral.com/73manl1.htm, Accessed: August 20, 2013.

Anon. (2008), "Technical Guidelines/Standards (Instructions) for Spatial Data Capture and Presentation in Ghana", Survey of Ghana, pp 2533.

Asante, E. S. (2011), "Mining Activities in Obuasi and Tarkwa Pollute 262 Rivers and Plague Residents with Keratosis and Diabetes", http://environmentalwatchman.blogspot.com/201 1/08/mining-activities-in-obuasi-tarkwa.html, Accessed: August 10, 2014.

Asklund, R. and Eldvall, B. (2005), "Contamination of Water Resources in Tarkwa Mining Area of Ghana", MSc Thesis, Department of Engineering Geology, Lund University, Lund, pp. 6-21.

Borshch-Komponiets, V., Navitny, A. and Knysh, G. (1989), Mine Surveying, Mir Publishers, Davis R. E., Foot, F. S., Anderson, J. M. and Mikhail, E.
M. (1981), Surveying, Theory and Practice, McGraw-Hill Inc, pp. 802-804

Garry K. (2009), "Retracement Surveys and Undocumented Monuments", The American Surveyor, Nov./Dec. 2009, Edition, Available at www.amerisurv.com, Accessed: August 20, 2013.

Ghilani, C. D. and Wolf, P. R. (2008), Elementary Surveying-An Introduction to Geomatics, Pearson Education Inc., pp. 69-70, 317-392.

Griffin R. J. (1960), "Retracement and Apportionment as Surveying Methods for Reestablishing Property Corners", Marquette Law Review, 43, pp. 484-510.

Hermansen, K. E. (1991), "Comments on Professional Responsibility", Available at: http://www.umaine.edu/set/svt/articles/ProfResp. pdf, Accessed: February 17, 2013.

Hermansen, K. E (1999), "GPS and Boundary Retracement", Available at: http://www.umaine. edu/set/svt/articles/GPS\&BdrySurv.pdf, Accessed: August 202013.

Hermansen, K. E. and Brown, C. (2006), "Innovations in Teaching Boundary Research". Available at: http://www.umaine.edu/set/svt/ articles/DigitalResearch.pdf, Accessed: February 19, 2013.

Lanfranki, J. (2013), "Boundary Retracement Survey of Cal Poly's Serrano Ranch", Polytechnic Project Work, Bio-Resource and Agricultural Engineering Department, California Polytechnic State University, San Luis Obispo. Available at http://digitalcommons.calpoly.edu, Accessed: August 20, 2013, pp. 33-38.

Kuma, J. S. and Ewusi, A. (2009), “Water Resources Issues in Tarkwa Municipality, Southwest Ghana", Ghana Mining Journal, Vol. 11, pp. 3745.

Kusi-Ampofo, S. and Boachie-Yiadom, T. (2012), "Assessing the Social and Environmental Impacts of Illegal Mining Operations in River Bonsa", Study Report, Business Sector Advocacy Challenge (BUSAC) and Pure FM, Tarkwa, Ghana, pp. 7-17.

Kwesi, E. A. A., Horror L. C. and Annan J. K. (2018), "Provision of Sanitation Maps for Improving Waste Management and Sanitation at the District Level: Case Study in the TarkwaNsuaem Municipality of Ghana", Conference Proceedings, 5th UMaT Biennial International Mining and Mineral Conference, 1st - 4th August, 2018, UMaT, Tarkwa, Ghana. pp. 15-20.

Mantey, (2014), 'Land Scape Elements Implicated by Buluri Ulcer Endemic Areas' PhD Report, Geomatic Engineering Dept, University of Mines and Technology (UMaT), Tarkwa, Ghana, pp. 1020.

Rose-Nolin, A. (2008), “The Next Generation: The Daily Problems of a Surveyor" Available at: http://www.profsurv.com. Accessed: February 17, 2013. 
Troy H. (2006), "Missouri/Iowa Boundary Line Investigation", The American Surveyor, March /April. 2006, Edition, Available at http://www .amerisurv.com, Accessed: August 6, 2012.

Wilson, D. A. (2009), "Rules of the Game: Griffin's Survey Methods: Retracement", The Professional Surveyor Magazine, March 2009, Volume 29, Issue 3, Available at http://www.profsurv.com/magazine, Accessed: August 6, 2012.

\section{Authors}

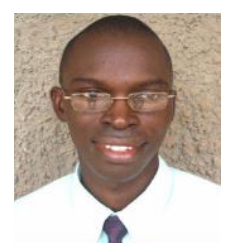

E. A. A. Kwesi is a Lecturer in Geomatic Engineering, a Professional Land Surveyor and Consultant in Land Acquisition and Compensations. He is currently working at the Geomatic Engineering Department of the University of Mines and Technology (UMaT), Tarkwa, Ghana. He holds MPhil. Degree in Mining Engineering from UMaT and BSc Degree in Geomatic Engineering from the Kwame Nkrumah University of Science and Technology (KNUST), Ghana. He is a member of GhIS, GhIG, FIG, SME and GLP. His research and consultacy works cover Surveying and Mapping, Community Involvement and Multicriteria Decision Making and their Applications in Sustainable Management of Land, Agriculture, Solid Waste and Community Development.

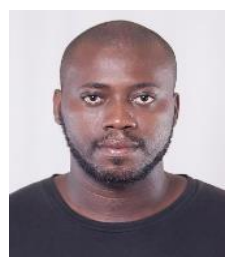

O. Ato Simpson is a GIS Analyst and Land Surveyor currently pursuing his MPhil Degree Education in Environment, Water and Sustainability at the University of Energy and Natural Resources (UENR), Sunyani, Ghana. He has a BSc. in Natural Resources Management with specialization in Land Reclamation and Restoration from the University of Energy and Natural Resources (UENR). He has over 5 years work experience and his research interest involves remote sensing and GIS applications in Land Reclamation and Restoration, Land use and land cover change detection and solid waste management.

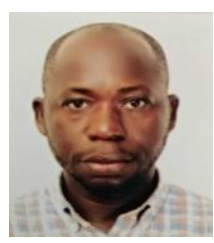

J. K. Lawerteh is currently working as Assistant Lecturer at the Geomatic Engineering Department of the University of Mines and Technology (UMaT), Tarkwa, Ghana. He has MSc and BSc. Degrees in Geomatic Engineering from UMaT. He is a member of GhIS and has over 10 years work experience in the field of Geomatics. His research interest involves the applications of GIS and Remote Sensing in Land and Environmental Management.

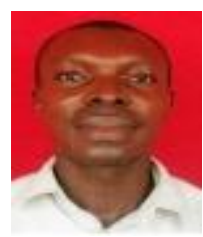

A. K. Mends is a Professional Graduate Teacher currently working with Ghana Education Service in Takoradi, Ghana. He holds a Bachelor's Degree Certificate in Education from the University of Education, Winneba and Teacher's Certificate 'A' from the University of Cape Coast in Ghana. He is currently pursuing postgraduate Diploma in Science Education. His research interest involves Environmental Health, Public Safety and Community Development.

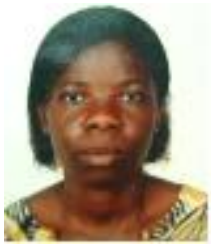

C. Assencher is a Professional Graduate Teacher currently working at Fiaseman Senior High Secondary School in Tarkwa, Ghana. She holds a Bachelor's Degree Certificate in Education from the University of Winneba, Certificate in Community Health Education from KNUST and

Teacher's Certificate "A" from the University of Cape Coast. Her research interest involves Community Health and Environmental Sanitation, Public Education and Community Involvement in Development.

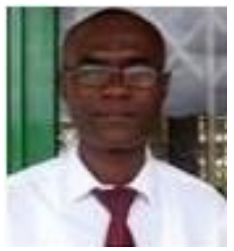

P. E. Baffoe is an Associate Professor in Geomatic Engineering at the Department of Geomatic Engineering, University of Mines and Technology, Tarkwa. He holds a $\mathrm{PhD}$ degree (Geomatic Engineering) from University of Mines and Technology. His research interests include Monitoring, Prediction and Modelling of Noise Levels, Application of GIS in Environmental issues, 3D Modelling, Digital Photogrammetry and Mine Surveying. 